\title{
Hybrid framework for investment project portfolio selection
}

\author{
Bogdan Rębiasz \\ AGH University of \\ Science and Technology \\ Krakow, Poland \\ Email: brebiasz@zarz.agh.edu.pl
}

\author{
Bartłomiej Gaweł \\ AGH University of \\ Science and Technology \\ Krakow, Poland \\ Email: bgawel@zarz.agh.edu.pl
}

\author{
Iwona Skalna \\ AGH University of \\ Science and Technology \\ Krakow, Poland \\ Email: skalna@agh.edu.pl
}

\begin{abstract}
Project selection is a complex multi-criteria decision making process that is influenced by multiple and often conflicting objectives. The complexity of the project selection problem is mainly due to the high number of projects from which an appropriate collection (an effective portfolio) of investment projects must be selected. This paper presents a new conception of a hybrid framework for construction of an effective portfolio of investment projects. The parameters of the considered model are described using both probability distributions and fuzzy numbers (possibility distributions). The proposed framework enables to take into account stochastic dependencies between model parameters and economic dependencies between projects. As a result, a set of Pareto optimal solutions is obtained. The performance of the proposed method is illustrated using an example from metallurgical industry.
\end{abstract}

\section{INTRODUCTION}

$\mathbf{T}$ HE of estimation and selection of investment projects is often named in literature as "capital budgeting". An effective capital budget (a portfolio of investments) is a budget which provides the maximum NPV (Net Present Value) for an acceptable level of risk or the lowest level of risk for a given acceptable NPV of a portfolio. The choice of an appropriate method for risk assessment is associated, among others, with the problem of description of uncertainty in business activity.

For many years, probabilistic calculus was considered as the only appropriate way to mathematically describe and deal with uncertainty. However, in real problems of assessing risk in business activity, not only randomness, but also imprecise or incomplete data is an important source of information. For this reason, many researchers often use alternative ways of modelling of uncertainty, such as fuzzy sets or interval numbers. Also for the selection of investment portfolio, the most appropriate approach to risk assessment is to develop and use methods that allow different representations of uncertainty (e.g., by probability distributions, fuzzy numbers and intervals) to be processed according to their nature and only finally combine them into a synthetic easy-to-interpret risk measure.

Another important aspect of defining an effective portfolio of investment projects is the analysis of the dependency problem. There are two kinds of dependency. The dependency between parameters is usually described statistically and, therefore, is called "statistical dependency"; statistical dependency is typically modelled by fuzzy or probabilistic correlation or regression. The second type of dependency is projects' interdependency, usually called "economic dependency". It is used to describe an interaction between investment projects. Interdependency is especially challenging to model, due to the difficulties with its description.

This paper briefly presents a novel framework for the selection of an efficient portfolio of investment projects. The proposed framework integrates a non-linear programming with tools that enable to describe interdependency between projects in a situation when model parameters are described both using probability distributions and fuzzy numbers. The paper has the following structure. Section II outlines different ways of description of uncertainty. In Section III, the current state of art in the selection of a portfolio of investment project is presented. A novel framework for the selection of an effective portfolio of investment projects is suggested in Section IV. In Section V a numerical example is solved using the proposed framework to demonstrate the effectiveness of the latter.

\section{DESCRIPTION OF UNCERTAINTY IN EVALUATION OF INVESTMENT PROJECTS}

Most of models of the real-world investment projects contain a mixture of quantitative and qualitative data. Therefore, increasingly often alternative descriptions of uncertainty in the assessment of the efficiency of investment projects are applied. The most common situation is when some parameters are described by probability distributions (statistical data), while others are given in the form of possibility degrees (subjective assessments of phenomena made by experts [27], [4]), i.e., the available data is heterogeneous in nature. To sum up, one may say, after Baudrit et al. [4], that randomness and imprecise or missing information are two reasons of uncertainty, which have an impact on the analysis of economic efficiency. Therefore, in the process of the evaluation of investment projects (estimation of efficiency and risk of projects), it is inevitable to deal with uncertainty caused by vagueness intrinsic to human knowledge and imprecision or incompleteness resulting from the limit of human knowledge [13], [20]. Hence, it is necessary to use a scheme for representing and processing vague, imprecise, and incomplete information in conjunction with precise and statistical data [4], [8], [13]. 
There are hardly a few studies that describe the use of hybrid data [25], i.e., data partially described by probability distributions, and partially by possibility distributions. The use of such data allows to reflect more properly the knowledge on parameters of economic calculus. However, very often, in the assessment of efficiency of investment projects, no distinction is made between these two types of uncertainty, both being represented by means of probability distributions [27]-[13]. Whereas, as suggested by Ferson and Ginzburg [11], distinct methods are needed to adequately represent random variability ("objective uncertainty") and imprecision ("subjective uncertainty").

\section{METHODS FOR THE SELECTION OF EFFECTIVE PORTFOLIOS OF INVESTMENT PROJECTS}

The problem of capital budgeting was for the first time formulated by Lorie and Savage [20]. Later on, it was solved using mathematical programming methods. First works on this subject date back to 1960s and 70s [6]-[2]. The problem of determining the capital budget was also solved using linear programming, linear programming with binary variables and multi-objective programming methods.

A lot of attention, especially in the recent years, is given to the risk of investment projects. A method for the construction of an effective portfolio of investment projects on the capital market was first presented by Markowitz [22]. Seitz has adopted the ideas of Markowitz for capital budgeting [26] by using the binary quadratic programming. Methods for the selection of an effective portfolio of investment projects are being constantly improved [7], [9], [1], [3], [24]. Probability distributions of selected parameters were used to describe the uncertainties in these models. In the literature, also presented are methods for the selection of a portfolio of investment projects in the case when uncertain parameters of efficiency calculus are described by means of fuzzy numbers. Such methods were proposed by Huang [15], [16] and Liu and Iwamura [19] and Kahraman [18].

Guyonnet et al. [13] has proposed a method which facilitates estimation of risk in the case when probability and possibility distributions are used simultaneously. This method was a modification of the method proposed previously by Cooper et al. [8]. Methods for processing hybrid data combine stochastic simulation with arithmetic of fuzzy numbers. As a result of processing of such data, Guyonnet et al. [13] define two cumulative distribution functions: optimistic and pessimistic. Similarly, Baudrit et al. [4] use probability and possibility distributions in risk analysis. As a result of processing of such data, authors obtain random fuzzy variable, which characterizes the examined phenomenon.

Dickinson et al. [10] presented a method for optimal scheduling of investment projects, which takes into account the fact that particular projects can be complementary or substitutive to each other. Santhanam and Kyparisis [29] presented a mathematical model for the selection of a portfolio from economically dependent investment projects associated with the development of information systems. Zuluaga et al. [31] presented a model that enables the selection and scheduling of economically dependent investment projects. However, the models of Dickson, Santhanam and Kyparisis and Zuluga do not take into account uncertainty of cash flows generated by investment projects and stochastic dependencies between projects. Medaglia et al. [23] proposed the usage of evolutionary algorithms for the selection of economically and stochastically dependent investment projects.

It must be, however, highlighted that there are no methods for the selection of effective investment portfolio, which could process hybrid data, e.g., data expressed in the form of fuzzy numbers and probability distributions. In most of the existing approaches, different ways of uncertainty representation are usually unified by transforming one form of uncertainty into another. Obviously, such transformation entails some problems. For example, transformation of a probability distribution into a possibility distribution causes the loss of information, whereas the opposite one requires additional information to be introduced. This leads to systematic errors in the estimation of efficiency. It is, therefore, necessary to elaborate a framework for representing and processing stochastic, vague, imprecise, and incomplete information in conjunction with precise data for selection of investment project portfolio. Such a framework should also be able to take into account stochastic and economic dependencies.

\section{A FRAMEWORK FOR THE SELECTION OF INVESTMENT PROJECT}

The process of building an effective capital budget consists of three phases [14]: strategic consideration, individual project evaluation and portfolio selection. Because the approach proposed here focuses on interdependency between projects, the problem of building an effective capital budget is divided into two models - portfolio selection model (PSM) and portfolio evaluation model (PEM). The purpose of first model is to find selection of the investment projects to gain the best evaluation parameters. Second model is used to determine evaluation parameters for a given set of investment projects.

\section{A. Projects interdependency in uncertain environment}

PSM focuses on the selection of projects. Most of project portfolio optimization methods and tools treat each project in a portfolio as an isolated entity. This leads to systematic errors in the estimation of risk and efficiency, and usually produces large overestimation. In order to eliminate these deficiencies, the interdependency between project should be considered. Three types of projects interdependencies are recognized in the literature: benefit, resource and technical [12].

Resources interdependency occurs when the demand for resources to develop projects independently is greater than amount of resources required when all of projects are selected. Benefit interdependency occurs when the total advantage of at least two independent projects increases or decreases when these projects are treated as interrelated. Technical interdependency occurs when there is a set of exclusive projects such that only one of them may be selected. 
There are five classes of project portfolio selection models [2]: ad hoc approaches (e.g., profiles), comparative approaches [28] (e.g., AHP), scoring models, portfolio matrices, and optimization models. PSM is multi criteria linear programming model, and PEM is non-linear programming model combined with stochastic simulation.

\section{B. Portfolio selection model (PSM)}

Let us consider a company which plans to launch $m$ potential projects. Due to the changing environment, the company must select a proper subset of those projects. Let each project create new or modify existing primary process steps. A portfolio of investment projects is defined as $\left(x_{1}, \ldots, x_{m}\right)$ and $x_{i}=1$ when project $i$ is selected and 0 otherwise $(i \in I=\{1, \ldots, m\})$. Let $b$ defines overall budget allocation for a selected portfolio, and $c_{i}$ initial cost of implementation of $i$-th investment. Let $\operatorname{fin}\left(x_{1}, \ldots, x_{m}\right)$ denote financial evaluation parameter for a given portfolio of investments. The performance of the selected portfolio is measured by two functions: $E\left(\operatorname{fin}\left(x_{1}, \ldots, x_{m}\right)\right.$ and $\sigma\left(f i n\left(x_{1}, \ldots, x_{m}\right)\right)$. Then, the selection of the portfolio of investments is defined as follows: find $\left(x_{1}, \ldots, x_{m}\right)$ that maximize of the expected value of $\operatorname{fin}\left(x_{1}, \ldots, x_{m}\right)$ and minimize $\sigma\left(\operatorname{fin}\left(x_{1}, \ldots, x_{m}\right)\right)$ subject to:

- portfolio selection constraints - for each investment, the cost of implementation cannot exceed the overall budget $\sum_{i \in I} c_{i} * x_{i} \leqslant b$

- integrability constraints: $x_{i} \in\{0,1\}, i \in I$

In order to solve PSO problem, for each portfolio of investments, PEM model must be invoked in order to compute evaluation parameters.

\section{Portfolio evaluation model (PEM)}

PEM computes evaluation parameters for a given set of investment projects $\left(x_{1}, \ldots, x_{m}\right)$. Since some of the model parameters are given as fuzzy numbers, thus, the value of the $\operatorname{fin}()$ function is a fuzzy variable, which results from the simulation combined with non-linear programming.

In order to evaluate a portfolio of investments, a mathematical model of an enterprise is built. Mathematical model consists of two groups of equations. First group of equations includes balances of the enterprise manufacturing capacities and material balances. It allows to determine size of the total production and size of sale achieved by enterprise. It determines also conditions of the selection of projects to be implemented. These conditions result form manufacturing capacities balance, material balances and availability of capital allocated for investments. The second group of equations are financial equations.

- equations of manufacturing capacities balance for primary production departments

$$
\sum_{i \in I} X_{i j w}^{t \tau} \leqslant v_{j w}^{\varsigma} \cdot \Delta_{j w}^{\tau}
$$

where $\tau=0, \ldots, \bar{\tau}, \tau \leqslant t, j \in J, w \in W_{j}$ and $t=\tau, \ldots, \tau+\bar{t}_{j w}$.

$$
\begin{gathered}
X_{i j w}^{t \tau} \geqslant 0, \varsigma=t-\tau \\
\Delta_{j w}^{\tau}= \begin{cases}1 & \text { for } w \in \bar{W} \\
0 & \text { for } w \in W-\bar{W}\end{cases} \\
\kappa(\bar{W})=1, \\
\eta^{\tau}(\bar{W}) \leqslant \bar{\eta}^{\tau}, \tau=0,1, \cdots, \bar{\tau}
\end{gathered}
$$

- equations of the enterprise material balance

$$
\begin{gathered}
\sum_{j \in J} \sum_{w \in W_{j}} \sum_{\substack{\tau=1 \\
\tau \leqslant t}}^{\bar{\tau}} X_{i j w}^{t, \tau}-\sum_{j \in J} \sum_{w \in W_{j}} \sum_{z \in I} \sum_{\substack{\tau=1 \\
\tau \leqslant t}}^{\bar{\tau}} m_{i z j w} X_{z j w}^{t, \tau}=G_{i}^{t} \\
G_{i}^{t} \leqslant \bar{g}_{i}^{t}(\bar{W})
\end{gathered}
$$

where:

- $X_{i j w}^{t \tau}$ - quantity of the gross output of product $i$ produced in $j$ department in $t$ year, in case of qualifying to realization project $w$ in $\tau$ year,

- $G_{i}^{t}$ - size of sale of the product $i$ in year $t$,

- $K R K^{t}$ - value of short-term credit in year $t$,

- $K R D^{t}$ - value of long-term credit in year $t$,

- $Z B^{t}$ - gross profit in year $t$,

- $I$ - set of product indexes,

- $I_{j}$ - set of indexes of products produced in $j$ department,

- $W$ - set of project indexes,

- $W_{j}$ - set of indexes of projects connected with $j$ department,

- $\bar{W}$ - set of indexes of projects qualified to realization,

- $J$ - set of primary production department indexes

- $v_{j w}^{\varsigma}$ - manufacturing capacity of the $j$ department after realization of $w$ project in $\varsigma$ year of the duration

- $\bar{\eta}^{\tau}$ - limit of investment outlays in the $\tau$ year,

- $m_{i z j w}$ - consumption per unit of the $i$ product for producing the $z$ product in the $j$ department after realizing the $w$ project,

- $\bar{t}_{j w}$ - duration of the $w$ project being realized in $j$ department

- $c_{i}^{t}$ - selling price for product $i$ in year $t$

- $k z_{i j w}^{\varsigma}$ - variable cost of processing the product $i$ by department $j$ after realization of $w$ project in $\varsigma$ year of the duration

- $r_{d}$ - long-term interest rate

- $r_{k}$ - short-term interest rate

$-\bar{\kappa}: 2^{W} \rightarrow\{0,1\}$ - function determining sets of projects being possible for realization, value 1 means a set possible to realization, value 0 means set impossible to realization,

- $\eta^{\tau}: 2^{W} \rightarrow R$ - function assigning to $\bar{W}$ set of the projects an investment outlay for realization of this set in $\tau$ year of capital budgeting period

- $\bar{g}_{i}^{t}: 2^{W} \rightarrow R$ - function assigning to $\bar{W}$ set of the projects possible sale of the product in the $t$ year

The second set of equations of the model are financial equations. They are linear equations, which for all the 
above-mentioned parameters determined by equations (1)-(7), determine specific items of the company's balance sheet, $\mathrm{P} \& \mathrm{~L}$ account and cash flows (NCF) used to calculate the NPV. As an example, an equation for calculating a company's gross profit is presented below.

$$
Z B^{t}=P-C_{1}-C_{2}-C_{3},
$$

where $i \in I ; t=0,1,2, \cdots, T$ and

$$
\begin{gathered}
P=\sum_{j \in J} \sum_{i \in I_{j}} c_{i}^{t} G_{i}^{t} \\
C_{1}=\sum_{\tau=1, \tau \leqslant t} \sum_{w \in W_{j}} \sum_{j \in J} \sum_{i \in I} k_{i j w}^{\varsigma} X_{i j w}^{t, \tau} \\
C_{2}=r_{k} K R K^{t}+r_{d} K R D^{t} \\
C_{3}=\chi^{t}(\bar{W})-\xi^{t}(\bar{W})
\end{gathered}
$$

The remaining financial equations express commonly known dependencies. A detailed presentation on them would considerably increase the volume of the article. Therefore, it is omitted.

In the next step, an appropriate model of uncertainty is assigned for every parameters. In the proposed framework, material consumption and product cost are characterized by fuzzy numbers. Demand and selling prices are described by probability distributions. Then, fuzzy simulation is employed, which allows different representations of uncertainty to be processed according to their nature. Moreover, the proposed framework takes into account economic dependencies in the process of selection of an effective portfolio of investment projects. Statistical dependency is used for describing relation between model parameters. Dependency between parameters characterized by fuzzy numbers are described by interval regression. Interval regression is an extension of the classical (crisp) regression where regression parameters are bounded closed intervals. For probabilistic parameters their dependency is determined by the correlation matrix. To process them, a method presented by Yang [30] based on Cholesky decomposition of the correlation matrix is utilized.

\section{Procedure of determining portfolio evaluation model}

The proposed procedure of determining the effectiveness of investment portfolio consists of two stages. It combines the procedure of stochastic simulation with execution of arithmetic operations on interactive fuzzy numbers. To execute such arithmetic operations non-linear programming is used. Computation procedure in this case is the following. Random variable values are drawn from among mentioned above parameters expressed in the form of the probability distribution. The procedure of generation accounts statistical dependency between variables. These values and remaining parameters expressed in the form of fuzzy numbers allow to determine evaluation parameter as fuzzy number. The problem of determining the fuzzy number characterizing evaluation parameter may be written owing to use of the concept of $\alpha$-levels of fuzzy sets. Thus, the variables $y$ corresponding to the parameters that are expressed in the form of fuzzy numbers are introduced, and then the parameters are replaced for those variables. Additionally, the following constraints are imposed:

$$
\begin{gathered}
\inf \left(\tilde{Y}_{i}\right)_{\alpha} \leq y_{i} \leq \sup \left(\tilde{Y}_{i}\right)_{\alpha} \\
y_{i} \geq \inf \left(a_{1}^{i z}\right) \cdot y_{z}+\inf \left(a_{2}^{i z}\right) \\
y_{i} \leq \sup \left(a_{1}^{i z}\right) \cdot y_{z}+\sup \left(a_{2}^{i z}\right)
\end{gathered}
$$

where

- $\inf \left(\tilde{Y}_{i}\right)_{\alpha}, \sup \left(\tilde{Y}_{i}\right)_{\alpha}$ - respectively lower and upper bounds of $\alpha$-level of the fuzzy parameter $\tilde{Y}_{i}$

$\sup \left(a_{1}^{i z}\right), \inf \left(a_{1}^{i z}\right)$,

- $\sup \left(a_{2}^{i z}\right), \inf \left(a_{2}^{i z}\right)$

bounds of interval regression coefficients describing dependency between parameters $\tilde{Y}_{z}$ and $\tilde{Y}_{i}$

Next, in order to determine the lower and upper bounds of the respective $\alpha$-level of the efficiency parameter, the following constrained optimization problems must be solved:

$$
N P V_{\alpha} \longrightarrow \min
$$

for the definition of the lower bound of the $\alpha$-level of the NPV,

$$
N P V_{\alpha} \longrightarrow \max
$$

for the definition of the upper bound of the $\alpha$-level of the NPV. Drawing probabilistic values and determining NPV is repeated $n_{\max }$ times. As result $n_{\max }$ fuzzy sets characterized by membership functions $\left(\mu_{1}^{N P V}, \ldots, \mu^{N P V}\right)$ are obtained and thus NPV is represented by a random fuzzy variable. Based on the vector $\left(\mu_{1}^{N P V}, \ldots, \mu^{N P V}\right)$, the mean value, standard deviation as well as lower and upper cumulative distributions for the NPV are calculated. The hybrid procedure which implements the described approach is presented in the following algorithm.

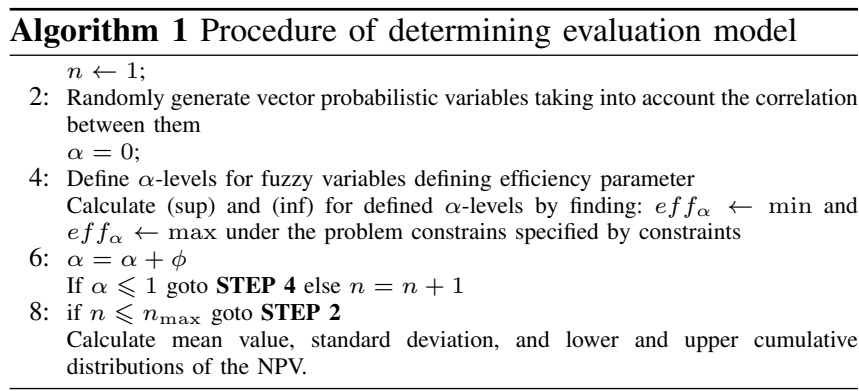

\section{NUMERICAL EXAMPLE}

The capital budget was determined for the production process presented on the fig. 1. This setup includes the production cycle in steel industry, from production of the pig iron, production of steel, hot rolling products to production products coated with metal and plastics.

We take into consideration five investment projects: steel making plant, hot rolled sheet mill, cold-rolled sheet mill, hot-dip galvanizing sheet plant, sheet organic 


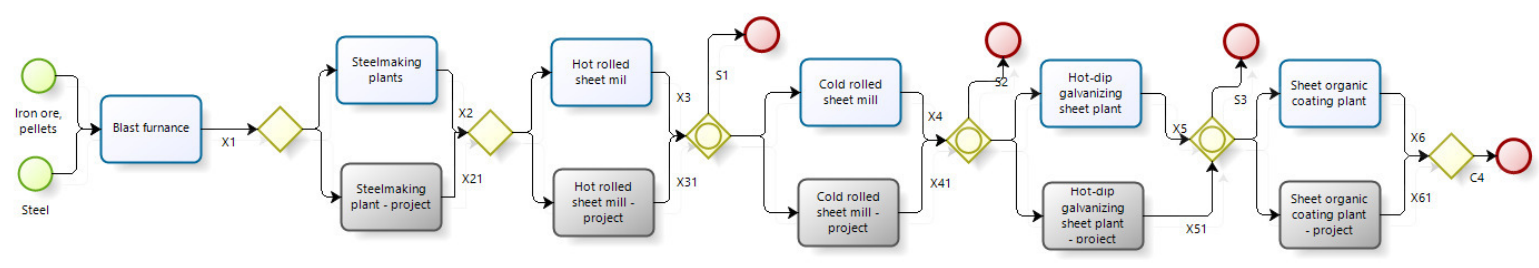

Fig. 1. Diagram of the analyzed technological setup

coating plant. Those investments are highlighted in gray. Decisive variables for the estimation of efficiency and the risk of investment projects in case of the investment in iron metallurgy are: quantity and selling prices, costs of materials and quantity of investment outlays. It was recognized also from here, that in the simulation experiment is necessary to take into consideration the uncertainty of the possible quantity of sale for each of products ranges being produced by the company, prices of these products, prices of metallurgic raw materials (prices of iron ores and the pellets), consumption per unit indexes, quantity of investment outlays. It was assumed, that remaining parameters of the efficiency calculus were determined. Prices of individual assortments of metallurgic products and metallurgic raw materials are correlated strongly. Similarly, sale quantities of each assortment of metallurgic products are correlated. This fact was taken into consideration when processing the values of efficiency calculus uncertain parameters.

In the computational experiment it was taken into consideration the uncertainty of the possible quantity of sales for each of products ranges being produced by the company, prices of these products, prices of semi-finished steel (prices of continuous casting stands), investment outlay for projects, construction period for investment projects and consumption per unit indexes for all products. Sales and possible quantity of sale for each product are described be probability distribution (in this case normal distribution). Rest of parameters were presented as a triangular fuzzy numbers.

In numerical example, we identify two types of dependencies. Prices of individual assortments of metallurgic products and metallurgic raw materials are correlated. Also sale quantities of each assortment of metallurgic products are correlated. Those parameters are using to describe benefit interdependency. Equations of manufacturing capacity balance are using for describing resource dependency and technical dependency.

The following new investment projects are considered: steel mill, rolling mill of cold milled steel sheets, hot dip galvanized coating, organic coating, rolling mill of hot milled steel sheets. Material consumption as well as product and half-product prices are given in the form of fuzzy numbers. They are presented, respectively, in Table I and Table II.

Sale parameters are given by normal probability distributions given in Table III.
TABLE I

TRAPEZOIDAL FUZZY NUMBERS (TFN) INDICATING MATERIAL CONSUMPTION

\begin{tabular}{lc}
\hline Material consumption & TFN \\
\hline steel half-products - molten iron & $(0.855,0.860,0.870,0.875)$ \\
\hline half-products - hot rolled steel sheets & $(1.058,1.064,1.075,1.078)$ \\
\hline hot rolled steel sheets - cold rolled sheets & $(1.105,1.111,1.124,1.130)$ \\
\hline cold rolled sheets - dip galvanized sheets & $(1.010,1.020,1.026,1.031)$ \\
\hline dip galvanized sheets - organic coated sheets & $(0.998,0.999,1.000,1.001)$ \\
\hline
\end{tabular}

TABLE II

TRAPEZOIDAL FUZZY NUMBERS (TFN) FOR PRICES

\begin{tabular}{lc}
\hline Price & TFN (USD/t) \\
\hline iron ore & $(335,360,400,425)$ \\
\hline lumps & $(375,400,440,470)$ \\
\hline steel scrap & $(940,960,1010,1035)$ \\
\hline hot rolled sheets & $(2040,2080.8,2177.7,2228.7)$ \\
\hline cold rolled sheets & $(2220.08,2266.65,2370.15,2427.08)$ \\
\hline $\begin{array}{l}\text { hot dip galvanized } \\
\text { sheets and strips }\end{array}$ & $(2535.75,2588.25,2709,2772)$ \\
\hline $\begin{array}{l}\text { organic coated } \\
\text { sheets and tapes }\end{array}$ & $(3450.6,3519.82,3684.9,3754.13)$ \\
\hline
\end{tabular}

TABLE III

PROBABILITY DISTRIBUTIONS INDICATING SALE PARAMETERS

\begin{tabular}{lcc}
\hline Sale & Mean value & Std. dev. \\
\hline hot rolled sheets & 4704.0 & 117.5 \\
\hline cold rolled sheets & 2750.0 & 51.4 \\
\hline hot dip galvanized - sheets and tapes & 1147.9 & 52.4 \\
\hline organic coated - sheets and tapes & 708.4 & 30.8 \\
\hline
\end{tabular}

The Cholesky matrix which describes the dependencies between sale parameters is given by the equation (18).

$$
\left(\begin{array}{llll}
1.00000 & 0.87786 & 0.91142 & 0.86321 \\
0.00000 & 0.47891 & 0.24007 & 0.27276 \\
0.00000 & 0.00000 & 0.33418 & 0.34165 \\
0.00000 & 0.00000 & 0.00000 & 0.25249
\end{array}\right)
$$

For the computational example, the $\alpha$-level for fuzzy variables are set at 10 and the number of simulation are set to 100 . The result for the computational example is shown in Fig. 2. 


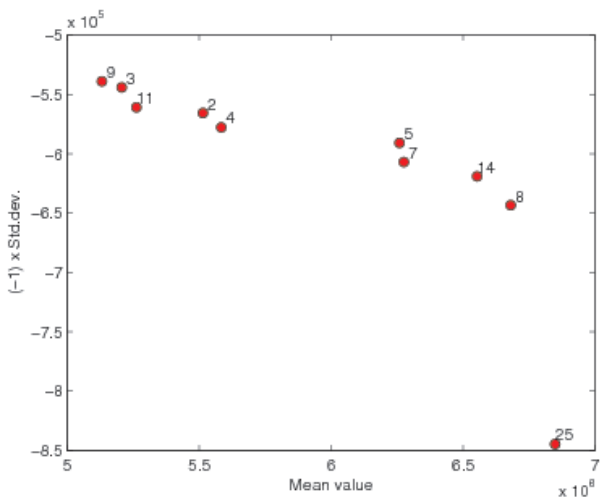

Fig. 2. Pareto optimal solutions for the problem of selection of an efficien portfolio of investment projects

\section{CONCLUSiOnS}

Above, the new method of choice of the effective portfolio of investment projects was presented. Presented concept of the mathematical model and the algorithm elaborated are making it possible to generate the set of Pareto-optimal solutions. The method is allowing for flexible formulating of dependence between projects. It concerns to dependencies with the technical character, how for example mutual excluding of projects. The structure of the model is causing, that dependencies with the economic character are also taken into account, it means, that projects are substitutionary or complementary in relation to themselves. Elaborated model has been utilized for selection of projects for the chosen production setup. The model is generating the set of Pareto-optimal solutions, which may to be the subject of the further analysis with taking extra criteria of quality into account.

\section{REFERENCES}

[1] J. April, F. Glover, J. P. Kelly, "OptFolio - A Simulation Optimization System For Project Portfolio Planning", in Proceedings of the 2003 Winter Simulation Conference, vol.1, 2003, pp. 301-309. (DOI:10.1109/WSC.2003.1261437)

[2] N. P. Archer, F. Ghasemzadeh. "An integrated framework for project portfolio selection", International Journal of Project Management, vol. 17(4), 1999, pp. 207-216. (DOI:10.1016/S0263-7863(98)00032-5)

[3] M. A. Badri, D. Davis, D. Davis, "A comprehensive 0-1 goal programming model for project selection", International Journal of Project Management, vol. 19(4), 2001, pp. 243-252. (DOI:10.1016/S0263-7863(99)00078-2)

[4] C. Baudrit, D. Dubois, D. Guyonet, "Joint Propagation and Exploitation of Probabilistic and Possibilistic information in Risk Assessment", IEEE Transaction on Fuzzy Systems, vol. 14, 2006, pp. 593-607. (DOI:10.1109/TFUZZ.2006.876720)

[5] R. H. Bernhard, "Mathematical programming models for capital budgeting.-survey, generalization and critique", J Financ Quant Anal, vol. 4, 1969, pp. 111-158. (DOI:10.2307/2329837)

[6] S. P. Bradley, S. C. Frey, "Equivalent Mathematical Programming Models of Pure Capital Rationing", J Financ Quant Anal, vol. 6, 1978, pp 345-361. (DOI:10.2307/2330391)

[7] W. T. Carleton, "Linear programming and Capital Budgeting Models: A New Interpretation", Journal of Finance, vol. 23, 1974, pp. 825-833. (DOI:10.1111/j.1540-6261.1969.tb01695.x)

[8] J. A. Cooper, S. Ferson, L. Ginzburg, "Hybrid processing of stochastic and subjective uncertainty data", Risk Analysis, vol. 16, 1996, pp. 785-791. (DOI:10.1111/j.1539-6924.1996.tb00829.x)
[9] P. K. De, D. Acharaya, K. C. Sahu, "A Chance-Constrained Goal Programming Model for Capital Budgeting", Journal for the Operational Research Society, vol. 33, 1982, pp. 635-638. (DOI:10.2307/2581726)

[10] M. W. Dickinson, A. C. Thomton, S. Graves, "Technology portfolio management. Optimizing interdependent projects over multiple time period", IEEE Transaction on Engineering Management, vol. 48(4), 2001, pp. 518-527. (DOI:10.1109/17.969428)

[11] S. Ferson, L. R. Ginzburg, "Difference method are needed to propagate ignorance and variability", Reliab Eng Syst Safe, vol. 54, 1996, pp. 133-144. ( DOI:10.1016/S0951-8320(96)00071-3)

[12] H. Eilat, B. Golany, A. Shtub, "Constructing and evaluating balanced portfolios of R\&D projects with interactions: A dea based methodology", Eur J Oper Res, vol. 172(3), 2006, pp. 1018-1039. (DOI:10.1016/j.ejor.2004.12.001)

[13] D. Guyonnet, B. Bourgine, D. Dubois, H. Fargier, B. Cme, P. J. Chils, "Hybrid Approach for addressing uncertainty in risk assessment", Journal of Environmental Engineering, vol. 126, 2003, pp. 68-76. (DOI:10.1061/(ASCE)0733-9372(2003)129:1(68))

[14] D. L. Hall, A. Nauda, "An interactive approach for selecting IR\&D projects", IEEE Trans. Eng. Management, vol. 37(2), 1990, pp. 126-133. (DOI:10.1109/17.53715)

[15] X. Huang, "Credibility-based chance-constrained integer programming models with fuzzy parameters", Information Sciences, vol. 176(18), 2006, pp. 2698-2712. (DOI:10.1016/j.ins.2005.11.012)

[16] X. Huang, "Fuzzy chance-constrained portfolio selection", Applied Mathematics and Computation, vol. 177(2), 2006, pp. 500-507. (DOI:10.1016/j.amc.2005.11.027)

[17] J. P. Ignazio, "An approach to the Capital Budgeting Problem with Multiple Objectives", The Engineering Economist, vol. 21, 1976, pp. 259-272. (DOI:10.1080/00137917608902798)

[18] C. Kahraman, D. Ruan, C. E. Dozdag, "Optimization of Multilevel Investments Using Dynamic Programming Based on Fuzzy Cash Flows", Fuzzy Optimization and Decision Making, vol. 2(2), 2003, pp. 101-122. (DOI:10.1023/A:1023443116850)

[19] B. Liu, K. Iwamura, "Chance constrained programming with fuzzy parameters", Fuzzy Sets and Systems, vol. 94(2), 1998, pp. 227-237. (DOI:10.1016/S0165-0114(96)00236-9)

[20] J. H. Lorie, L. J. Savage, "Three problems in capital rationing", Journal of Business vol. 28, 1955, pp. 229-239. (DOI:10.1086/294081)

[21] P. Lusztig, B. Schwab, "A Note of the Application of Linear Programming to Capital Budgeting", J Financ Quant Anal, vol. 3, 1968, pp. 427-431. (DOI:10.2307/2329582)

[22] H. M. Markowitz, Portfolio Selection Efficient Diversification of Investment, Wiley, New York, 1959.

[23] A. L. Medaglia, S. B. Graves, J. L. Ringuest, "A multiobjective evolutionary approach for linearly constrained project selection under uncertainty", Eur J Oper Res, vol. 179(3), 2007, pp. 869-894. (DOI:10.1016/j.ejor.2005.03.068)

[24] D. L. Olson, Decision Aids for Selection Problems, New York, Springer Series in Operations Research, 1996.

[25] B. Rębiasz, "Selection of efficient portfoliosprobabilistic and fuzzy approach, comparative study", Computers \& Industrial Engineering, vol. 64(4), 2013, pp. 1019-1032. (DOI:10.1016/j.cie.2013.01.011)

[26] N. E. Seitz, Capital Budgeting and Long-Term Financing Decisions. 3rd ed. USA, Dryden Press, 1999.

[27] B. Rębiasz, "Fuzziness and randomness in investment project risk appraisal", Computers and Operations Research, vol. 34, 2007, pp. 199-210 (DOI:10.1016/j.cor.2005.05.006).

[28] B. Rẹbiasz, B. Gaweł, I. Skalna, "Fuzzy multi-attribute evaluation of investments", in Proceedings of the Federated Conference on Computer Science and Information Systems (FedCSIS), 2013.

[29] R. Santhanam , G. J. Kyparisis, "A decision model for interdependent information system project selection", European Journal of Operational Research, vol. 89(2), 1996, pp. 380-399. (DOI:10.1016/0377-2217(94)00257-6)

[30] I.-T. Yang, "Simulation-based estimation for correlated cost elements", International Journal of Project Management, vol. 23(4), 2005, pp. 275-282. (DOI:10.1016/j.ijproman.2004.12.002)

[31] A. Zuluaga, J. Sefair, A. Medaglia, "Model for the Selection and Scheduling of Interdependent Projects", in Proceedings of the 2007 Systems and Information Engineering Design Symposium, University of Virginia, 2007. (DOI:10.1109/SIEDS.2007.4374020) 